\title{
О НЕКОТОРЫХ ВОПРОСАХ УЧАСТИЯ ПРОКУРОРА В АДМИНИСТРАТИВНОМ СУДОПРОИЗВОДСТВЕ
}

Аннотация. Предметом исследования в настоящей статье являются общие вопросы правового статуса прокурора как участника рассмотрения судами общей юрисдикции дел в рамках административного судопроизводства, регламентируемого нормами недавно вступившего в силу Кодекса административного судопроизводства Российской Федерации. Автор, проводя сравнительные параллели с действующим Гражданским процессуальным кодексом Российской Федерации, подчеркивает положительные стороны новелл, а также критически оценивает имеющие место, по его мнению, недостатки в правовом регулировании рассматриваемых им вопросов, вносит предложения, направленные на совершенствование правовых норм. При работе над статьей автором избран прежде всего сравнительно-правовой метод в контексте сопоставления норм законодательства, регламентирующего процедуры гражданского и административного судопроизводства. Проведенное исследование позволило автору определить положительные стороны новелл, внесенных законодателем в правовой статус прокурора, участвующего в административном судопроизводстве, а также обратить внимание на отдельные недоработки в формулировках процессуального законодательства и предложить в связи с этим возможные пути совершенствования некоторых норм. Новизна исследования заключается в том, что оно является одним из первых работ, посвященных правовому статусу прокурора, участвующего в административном судопроизводстве..

Ключевые слова: административное исковое заявление, административное судопроизводство, административное дело, заключение прокурора, защита прав граждан, категория дел, неопределенный круг лии, прокурор, публичный интерес, суд общей юрисдикции.

Abstract. The research subject is the range of general questions of the prosecutor's legal status as a participant of administrative proceedings, regulated by the recently adopted Code of Administrative Code Proceedings of the Russian Federation. The author compares the Code's provisions with the existing Civil Procedural Code of the Russian Federation, emphasizes the positive sides of the novels and criticizes the shortcomings of legal regulation of the issues under consideration, offers the ways to improve legal norms. The author applies the comparative-legal method to compare the provisions of the legislation, regulating administrative and civil proceedings. The author defines the advantages of the novels, added to the legal status of the prosecutor, involved in administrative proceedings, and draws attention to the particular drawbacks in procedural legislation formulae, offering the possible ways of their improvement. This research is one of the first scientific works, devoted to the legal status of the prosecutor, involved in administrative proceedings.

Key words: administrative bill of complaint, administrative proceedings, administrative case, prosecutor's decision, protection of rights of citizens, category of cases, general public, prosecutor, public interest, general jurisdiction court.

$\mathrm{C}$ 15 сентября 2015 г. вступил в силу Кодекс административного судопроизводства Рос(далее - КАС РФ) [1], что ознаменовало собой определение позиции законодателя по существу закрепленной в ч. 2 ст. 118 Конституции Российской Федерации [2] одной из форм судопроизводства, в которых осуществляется судебная власть в России, - административного. Отмечая безусловно положительный аспект самого факта принятия названного кодифицированного акта, тем не менее попутно отметим, что он породил вполне определенный юридический казус, заключающийся в том, что за рамками конституционно обозначенных форм судопроизводства (конституционного, гражданского, административного и уголовного) осталась сфера применения судами норм Кодекса Российской Федерации об административных пра- 
вонарушениях от 30.12.2001 № 195-Ф3 [3] в части рассмотрения судами общей юрисдикции соответствующих дел, что, по нашему мнению, даже в силу названия указанной категории дел должно было бы относиться к административному судопроизводству, а также деятельность арбитражных судов, которые в соответствии со ст. 1 Арбитражного процессуального кодекса Российской Федерации от 24.07.2002 № 95-Ф3 [4] осуществляют правосудие по правилам, установленным законодательством о судопроизводстве в арбитражных судах. При этом вполне очевидно, что арбитражные суды функционируют как в рамках гражданского (споры между субъектами предпринимательской и иной экономической деятельности), так и административного (по делам, возникающим из публичных правоотношений, включая применение главы 25 «Рассмотрение дел об административных правонарушениях») судопроизводства.

Вместе с тем воспримем отмеченные законодательные новеллы как данность и попытаемся подчеркнуть особенности норм КАС РФ, формирующих правовой статус прокурора в административном судопроизводстве, в сопоставлении с соответствующими нормами Гражданского процессуального кодекса Российской Федерации от 14.11.2002 № 138-Ф3 (далее - ГПК РФ) [5], который, собственно, и послужил тем «донорским» материалом, на основе которого были сформулированы категории дел, рассматриваемые судами общей юрисдикции в рамках административного судопроизводства. Поскольку в нашу задачу не входит развитие глубокой полемики по вопросу правомерности, а тем более разумности отнесения тех или иных споров к подведомственности судов именно в рамках рассматриваемой формы судопроизводства либо, напротив, игнорирования законодателем очевидных для кого-то вопросов, коль скоро по этой проблематике успели высказаться все неравнодушные процессуалисты еще на стадии обсуждения законопроекта [6], полагаем возможным сосредоточиться на отдельных сущностных моментах, имеющих значение именно для органов прокуратуры, призванных в силу п. 2 ст. 1 Федерального закона «0 прокуратуре Российской Федерации» (далее - Закон о прокуратуре) [7] защищать права и свободы человека и гражданина, а также охраняемые законом интересы общества и государства.

Итак, также как и в ст. 34 ГПК РФ, в ст. 37 КАС РФ прокурор определен как лицо, участвующее в деле. Вместе с тем новым Кодексом статус прокурора повышен до административного истца в случае, когда прокурор обращается в суд для реализации возложенных на него публичных функций (ч. 2 ст. 38 КАС РФ). В этой связи позволим себе не согласиться с позицией Ю.Г. Насонова и В.С. Вы- скуба, отмечающих, что «как и в гражданском процессе, прокурор не является стороной по делу, возбужденному по его административному иску, что вытекает из содержания названной статьи (37 прим. A.B.) Кодекса» [8, с. 62]. Дело в том, что в силу ч. 1 ст. 38 КАС РФ сторонами в административном деле являются административный истец и административный ответчик, а поскольку прокурор вправе в указанном выше случае выступать в роли административного истца, то ответ на вопрос, является ли он при этом стороной дела, вполне очевиден.

В этом нам видится не только новый подход по сравнению с гражданским судопроизводством к позиционированию роли прокурора, но и создание внутреннего противоречия в приведенной норме, согласно которой под административным истцом в первую очередь выступает лицо, в интересах которого подано заявление, в том числе прокурором. Поясним, что коль скоро в силу ст. 1 Закона о прокуратуре прокуратура осуществляет от имени Российской Федерации функцию надзора и иные установленные федеральными законами функции, таковые априорно следует рассматривать как публичные. При этом, реализуя традиционно признаваемую в науке о прокурорской деятельности за прокуратурой функцию участия в рассмотрении дел судами, прокурор выполняет задачи, связанные в том числе с защитой прав и свобод человека и гражданина, охраняемых законом интересов общества и государства. Таким образом, по нашему мнению, законодатель немотивированно объединил в одном лице, то есть в прокуроре, административного истца и лицо, выступающее в интересах административного истца. В этом смысле позиция, закрепленная в ГПК РФ, как нам представляется, является более правильной. Безусловно, прокурор может выступать в качестве материального истца в случаях, когда чьими-то действиями (бездействием) создаются препятствия в осуществлении непосредственно прокурорской деятельности, но это отдельная тема для исследования.

В силу ч. 5 ст. 38 КАС РФ прокурор, хотя он прямо не называется в этой норме, может выступать в качестве административного ответчика как носитель публичных полномочий, в чем можно согласиться с Ю.Г. Насоновым и В.С. Выскубом [8, с. 62], которые, к сожалению, в содержательном плане не уточняют свою позицию. В свою очередь поясним, что в соответствии со ст. 17 рассматриваемого кодифицированного акта Верховный Суд Российской Федерации, нижестоящие суды общей юрисдикции рассматривают и разрешают административные дела, связанные с защитой нарушенных или оспариваемых прав, свобод и законных интересов граждан, прав и законных интересов организаций, 


\section{Административное и муниципальное право 2 (98) • 2016}

а также другие административные дела, возникающие из административных или иных публичных правоотношений и связанные с обоснованностью осуществления государственных или иных публичных полномочий. В этой связи обжалование незаконных, по мнению заявителей, действий (бездействия) и решений прокуроров при осуществлении последними надзорной деятельности, связанной с реализацией властных полномочий, вполне допустимо и мы можем с большой долей вероятности прогнозировать, что интенсивность обращений по этому поводу соответствующих лиц в суды будет возрастать по мере наработки судебной практики. Однако этот вопрос также заслуживает самостоятельного исследования, в силу чего обратим внимание на характеристику изначально обозначенного процессуального положения прокурора.

Статья 39 КАС РФ, конкретизирующая статус прокурора, участвующего в деле, с одной стороны, представляет собой определенную аналогию со ст. 45 ГПК РФ, регламентирующей особенности правового положения прокурора как участника гражданского процесса. Обе статьи в первых частях в качестве объектов защиты, которую призван обеспечить своей инициативой прокурор, выделяют права, свободы и законные интересы граждан, неопределенный круг лиц или интересы Российской Федерации, ее субъектов, муниципальных образований. Правда, в КАС РФ дополнительно оговариваются «другие случаи, предусмотренные федеральными законами». Полагаем, что под данную формулировку подпадает, например, основание, закрепленное в п. 4 ст. 27 Закона о прокуратуре и допускающее в качестве побудительного мотива для обращения прокурора в суд с административным иском приобретение нарушением «особого общественного значения в силу иных обстоятельств». Вопрос правильного восприятия этой нормы судебной практикой очевидно следует отложить до четкого обозначения соответствующей позиции на сей счет Пленума Верховного Суда Российской Федерации либо восприятия в качестве прецедентных решений, принятых в порядке пересмотра постановлений нижестоящих судов. Однако, как представляется, в любом случае без должной активности самих прокуроров, на которых лежит груз ответственности за выполнение стоящих пред ними задач, оптимальный подход может вырабатываться неопределенно долго. Напомним, что ст. 45 ГПК РФ не оперирует такого рода положением, в силу чего приведенная норма Закона о прокуратуре до недавнего времени не могла приниматься во внимание судами общей юрисдикции, а прокурорами - как руководство к действию.

Схожими являются положения о том, что заявление в защиту прав, свобод и законных интересов гражданина может быть подано прокурором только в случае, если гражданин по состоянию здоровья, возрасту, недееспособности и другим уважительным причинам не может сам обратиться в суд. Однако, в ч. 1 ст. 39 КАС РФ нет присутствующей в сравниваемой норме гражданского процессуального законодательства оговорки о том, что указанное ограничение не распространяется на заявление прокурора, основанием для которого является обращение к нему граждан о защите отдельных групп нарушенных или оспариваемых прав. Полагаем, что законодатель необоснованно проигнорировал эту конструкцию, включенную весной 2009 г. в ГПК РФ по результатам анализа последствий, которые повлек за собой мировой финансовый кризис, глубоко коснувшийся России и высветивший многочисленные проблемы, связанные с механизмом защиты гражданами своих прав.

Таким образом, решая вопрос об инициировании рассмотрения дела в рамках административного судопроизводства, прокурор должен обладать убедительной мотивацией своего правомочия на защиту прав, свобод и законных интересов физических лиц, подпадающих под указанные выше категории, о чем прямо говорится в ч. 6 ст. 125 КАС РФ. И здесь можно констатировать, что налицо различные подходы в определении правозащитного потенциала прокурора в рамках единой системы судов общей юрисдикции, а ведь, например, именно необходимостью обеспечения единой практики не столь давно согласно официальной версии была мотивирована ликвидация Высшего Арбитражного Суда Российской Федерации.

Часть 4 ст. 39 КАС РФ фактически копирует положение ч. 2 ст. 45 ГПК РФ о том, что прокурор, обратившийся в суд заявлением, пользуется процессуальными правами и несет процессуальные обязанности административного истца (за исключением права на заключение соглашения о примирении и обязанности по уплате судебных расходов). При этом новый кодифицированный акт обязывает прокурора уведомлять гражданина или его законного представителя о своем отказе от поданного им в интересах гражданина административного иска, чего не наблюдается в гражданском процессуальном законе.

В КАС РФ более детализирована и изменена позиция законодателя по вопросу о правовых последствиях, связанных с отказом прокурора от заявленных требований. Так, в силу ч. 2 ст. 45 ГПК РФ в случае отказа прокурора от заявления, поданного в защиту законных интересов другого лица, рассмотрение дела по существу продолжается, если это лицо или его законный представитель не заявит об отказе от иска. При отказе истца от иска суд прекращает производство по делу, если это не 
противоречит закону или не нарушает права и законные интересы других лиц.

В свою очередь ч. 6 ст. 39 КАС РФ определяет, что в случае отказа прокурора от административного иска, поданного в защиту прав, свобод и законных интересов гражданина, суд оставляет соответствующее заявление без рассмотрения, если гражданин, обладающий административной процессуальной дееспособностью, его представитель или законный представитель гражданина, не обладающего административной процессуальной дееспособностью, не заявит об отказе от административного иска. Как видим, новый Кодекс предусматривает:

1) отказ прокурора от своих требований, заявленных в защиту не только законных интересов гражданина, но и его прав и свобод;

2) иные последствия такого отказа, выражающиеся не в продолжении судом рассмотрения дела, а в оставлении заявления прокурора без рассмотрения при отсутствии отказа от административного иска уполномоченных на то лиц;

3) расширение круга лиц, имеющих право отказаться от административного иска, с гражданина или его законного представителя до представителя. Однако в силу ч. 4 ст. 39 КАС РФ на прокуроре лежит обязанность уведомления об отказе от административного иска почему-то только гражданина или его законного представителя, то есть представитель, по мнению законодателя, информироваться не должен, что впрочем не ущемляет прокурора в возможности сделать это инициативно. Упомянутые выше Ю.Г. Насонов и В.С. Выскуб уточняют, что обязанность прокурора уведомлять гражданина об отказе предусмотрена также в Законе о прокуратуре, что не вполне понятно в отсутствие соответствующей нормы в этом законодательном акте, и высказывают мнение, что «в своем уведомлении прокурор должен объяснить причины отказа от административного иска и разъяснить процессуальные права гражданина» [8, с. 64]. Кодекс не содержит подобного требования, но оно возможно найдет свое отражение в организационно-распорядительном документе Генерального прокурора Российской Федерации по рассматриваемому вопросу, по крайней мере, в части мотивировки изменения прокурором своей позиции.

Указанные авторы отмечают, что «процессуальный порядок действий суда в случае отказа прокурора от иска, поданного в защиту гражданина, некорректен» [8, с. 64], мотивируя это в том числе и тем, что закон не устанавливает срок на принятие гражданином (очевидно не только им, но и его представителями - прим. A.B.) решения, с чем в принципе можно согласиться. В определенной степени понятна озабоченность указанных авторов о том, «какую позицию займет суд, если гражданин не заявит об отказе либо обратится с просьбой о рассмотрении дела по существу?» [8, с. 64]. Как представляется, в первом случае (по умолчанию) дело не может рассматриваться в силу отсутствия воли гражданина (его представителя) на это. При наличии же положительного волевого решения рассмотрение судом административного дела очевидно. Однако желательно закрепить соответствующие позиции в самом Кодексе.

В случае отказа названных лиц от административного иска суд принимает отказ от него и прекращает производство по административному делу, что буквально повторяет приведенную выше схожую норму ч. 2 ст. 45 ГПК РФ. Вместе с тем необходимо учитывать оговорку законодателя о том, что отказ принимается, если это не противоречит закону и не нарушает права, свободы и законные интересы других лиц.

Кроме того, согласно ч. 5 ст. 39 КАС РФ в случае отказа прокурора от административного иска, поданного в защиту прав, свобод и законных интересов неопределенного круга лиц, являющихся субъектами административных и иных публичных правоотношений, рассмотрение административного дела по существу продолжается. Как видим, здесь речь идет не о конкретном лице, чьи интересы передумал защищать прокурор, а о неопределенном круге лиц, что является новеллой. Правда, в этой связи возникает вполне естественный вопрос о том, а кто же собственно будет защищать вместо выбывшего прокурора интересы этого самого неопределенного круга лиц, которые возможно и не в курсе того, что прокурор сначала решил вступиться за них, а затем по каким то представляющимся ему убедительными причинам расхотел. В этой же части ст. 39 законодатель оговаривает, что при отказе прокурора от административного иска в связи с удовлетворением административным ответчиком заявленных требований суд принимает такой отказ и прекращает производство по административному делу.

Продолжая мысль о полноте регулирования последствий отказа прокурора от исковых требований (а этот недостаток в еще большей степени присущ и ст. 45 ГПК РФ), отметим, что в ст. 39 КАС РФ следовало бы оговорить правовые последствия отказа прокурора от исковых требований, заявленных в защиту интересов Российской Федерации, ее субъектов и муниципальных образований в случаях, не связанных с добровольным удовлетворением ответчиком требований прокурора. Законодатель этот вопрос проигнорировал, хотя, по нашему мнению, необходимо было предусмотреть возможность представителей соответствующих публичных образований (государственных и му- 


\section{Административное и муниципальное право 2 (98) • 2016}

ниципальных органов, организаций и т.д.) продолжать защиту своих интересов.

В части 2 ст. 39 КАС РФ определена компетенция прокуроров и их заместителей по обращению с административными заявлениями в суды различных звеньев, рассматривающих административные дела, и это можно воспринимать положительно, поскольку в ст. 45 ГПК РФ подобный подход законодателя отсутствует, что тем не менее не вызывает на практике ситуаций с нарушением конкретными прокурорами правил субординации (компетенции).

Также как и в ч. 3 ст. 45 ГПК РФ, частью 7 ст. 39 КАС РФ предусмотрена вторая форма участия прокурора в рассмотрении дел судом - вступление в процесс с целью дачи заключения, причем оговаривается, что речь идет исключительно о случаях, предусмотренных в самом Кодексе, что является отличительным признаком. При этом законодатель подчеркнул, что прокурор не дает заключение по административному делу, если оно возбуждено на основании его административного искового заявления. В этом смысле в ч. 3 ст. 45 ГПК РФ опре- делено, что прокурор вступает в процесс и дает заключение по делам о выселении, о восстановлении на работе, о возмещении вреда, причиненного жизни или здоровью, а также в иных случаях, предусмотренных этим Кодексом и другими федеральными законами, в целях осуществления возложенных на него полномочий, то есть выносит основания для участия в рассмотрении дела за рамки процессуального законодательства.

Таким образом, подводя итоги сказанному, отметим, что вступивший в силу КАС РФ внес элементы новизны в реализацию органами прокуратуры функции участия в рассмотрении дел судами. В нашу задачу не входил детальный анализ всех положений Кодекса, затрагивающих правовое положение прокурора в административном процессе, что, очевидно, невыполнимо в рамках конкретно взятой статьи. Однако круг затронутых вопросов ставит на повестку дня потребность во внесении ряда законодательных корректив, а также определения Пленумом Верховного Суда Российской Федерации позиций по отдельным проблемным аспектам.

\section{Библиография:}

1. СЗ РФ. - 2015. - № 10. - Ст. 1391 (с послед. изменениями).

2. СЗ РФ. - 2014. - № 34. - Ст. 4398.

3. СЗ РФ. - 2002. - № 1 (ч. 1). - Ст. 1 (с послед. изменениями).

4. СЗ РФ. - 2002. - № 30. - Ст. 3012 (с послед. изменениями).

5. СЗ РФ. - 2002. - № 46. - Ст. 4532 (с послед. изменениями).

6. Сахнова Т.В. Достижимо ли единство цивилистического процесса? (в контексте концепции единого ГПК РФ и Кодекса административного судо-производства) // Арбитражный и гражданский процесс. - 2015. - № 4. С. 3 - 10;

7. Серков П.П. Актуальные вопросы совершенствования административного судопроизводства в Российской Федерации // Административное право и процесс. - 2015. - № 2. - С. 29 - 33 и др.

8. СЗ РФ. - 1995. - № 47. - Ст. 4472 (с послед. изменениями).

9. Насонов Ю.Г., Выскуб В.С. О недостатках правового регулирования участия прокурора в административном судопроизводстве // Вестник Академии Генеральной прокуратуры Российской Федерации. - 2015. - № 5. - С. 60-66.

\section{References (transliterated):}

1. $\quad$ SZ RF. - 2015. - № 10. - St. 1391 (s posled. izmeneniyami).

2. $\quad$ SZ RF. - 2014. - № 34. - St. 4398.

3. SZ RF. - 2002. - № 1 (ch. 1). - St. 1 (s posled. izmeneniyami).

4. $\quad$ SZ RF. - 2002. - № 30. - St. 3012 (s posled. izmeneniyami).

5. SZ RF. - 2002. - № 46. - St. 4532 (s posled. izmeneniyami).

6. Sakhnova T.V. Dostizhimo li edinstvo tsivilisticheskogo protsessa? (v kontekste kontseptsii edinogo GPK RF i Kodeksa administrativnogo sudo-proizvodstva) // Arbitrazhnyi i grazhdanskii protsess. - 2015. - № 4. - S. 3 - 10;

7. Serkov P.P. Aktual'nye voprosy sovershenstvovaniya administrativnogo sudoproizvodstva v Rossiiskoi Federatsii // Administrativnoe pravo i protsess. - 2015. - № 2. - S. 29 - 33 i dr.

8. SZ RF. - 1995. - № 47. - St. 4472 (s posled. izmeneniyami).

9. Nasonov Yu.G., Vyskub V.S. O nedostatkakh pravovogo regulirovaniya uchastiya prokurora v administrativnom sudoproizvodstve // Vestnik Akademii General'noi prokuratury Rossiiskoi Federatsii. - 2015. - № 5. - S. 60-66. 